gous compounds of the carbon series, free from nitrogen.

McMaster UNIVERsity,

J. Bishop Tingle

Toronto, Canada, December 16, 1908

\section{RUSSIAN RESEARCH IN METABOLISM}

THE activity of Russian investigators in problems of animal nutrition and metabolism in general has been but imperfectly noted by the large majority of workers in metabolism. This is in large part due to the fact that in spite of increasing interest in international cooperation in scientific research in all branches, the Russian language remains, and probably will continue to remain, a distinctly unintelligible vehicle for conveying scientific communications to the world at large. More recently at least one Russian journal is issuing simultaneously an edition in French.

Recognizing the great importance of many of the earlier Russian researches, the Office of Experiment Stations of the U. S. Department of Agriculture has from time to time had translated and published abstracts of much of the Russian research in that particular branch of science dealing with metabolism. These abstracts were translated in large part by Professor Peter Fireman, formerly of the George Washington University, and the admirable digest of metabolism experiments by Atwater and Langworthy ${ }^{1}$ contains many of them.

A dissertation entitled "Production of Heat by Healthy Man in the Condition of Comparative Rest," by A. Likhachev, is especially valuable as giving a complete description and tests of the Pashutin respiration calorimeter. This was translated at the instance of the Office of Experiment Stations, U. S. Department of Agriculture, by Dr. Fireman. Copies of the translation are on file at the Nutrition Laboratory and also at the Office of Experiment Stations, U. S. Department of Agriculture.

In connection with the preparation for pub-

${ }^{1}$ Bulletin 45, Office of Experiment Stations, U. S. Department of Agriculture, 1898. lication of the results of a series of experiments on fasting men made at Wesleyan Uni-i versity, I arranged with a young Russian school teacher, H. Levin, to translate completely a lengthy article entitled "Metabolism during Fasting," by A. Sadovyen. This article is of interest in that it describes a series of experiments on a fasting man in the Pashutin respiration chamber. The translation is preserved in the reading room of this laboratory.

On a recent visit to a number of European laboratories it was my good fortune to include several of the laboratories in St. Petersburg, and there I came into intimate contact with a great deal of research which was to me wholly unknown. I found that in certain instances the briefest kind of an abstract had been noted in some of the German abstract journals, but nothing approximating an adequate digest of this work had appeared as yet in anything but Russian. Thanks to the kindness of Professors Likhachev and Avroroff and Dr. Kartaschefsky, many important monographs were placed in my hands and, on my return to America, arrangements were made for their translation.

Professor Likhachev sent to the Nutrition Laboratory a copy of Pashutin's treatise on experimental pathology. This large work, consisting of two bulky volumes, contains a great deal of new, unpublished material, particularly in the section (some 800 pages) dealing with inanition. During the past year the whole section on inanition has been completely translated by Michel Groosenberg. This valuable work contains a large amount of original material, chiefly from Albitsky's laboratory, and is of importance to all workers in animal or human nutrition. The translation has been typewritten, manifolded and bound and copies of this translation are deposited in the surgeon general's library in Washington, the New York Public Library, and in the John Crerar Library in Chicago. Two other monographs presenting the results of experiments on man in the Pashutin respiration calorimeter are "The Influence of Alcohol on the Heat and Gas Exchange in 
Man" and "Investigations of Gas and Heat Exchange in Fevers," both by A. Likhachev and P. Avroroff. Finally, two articles by Dr. Kartaschefsky reporting experiments with the simall Pashutin respiration apparatus have been translated. They are entitled "The Influence of a Lack of Oxygen on the Exchange of Matter and the Heat Production in Animals" and "On the Influence of the Surrounding Temperature upon Animals in a Gas-Atmosphere poor in Oxygen."

These articles were translated in part by Mr. Alexander Rose, of Boston, Mr. Michel Groosenberg and Miss Anna Monossowitch, who is at present engaged in Russian translation at the Nutrition Laboratory.

Thus it is hoped to keep American workers in nutrition in more intimate contact with the admirable Russian researches that have as yet been practically inaccessible. Arrangements have been made with Professor Likhachev whereby all articles dealing with problems of metabolism can be sent to this laboratory for translation. From time to time the titles and short abstracts of these articles will be published in some scientific journal.

NUtrition Laboratory,

Francis G. Benediot

CARNEGIE InsTTtution OF WASHINGTON, Vila Street, Boston, Mass.

\section{SPEOIAL ARTIOLES}

A MENDELIAN VIEW OF SEX-HEREDITY

Two important contributions have recently been made to the discussion of sex-inheritance. In each a somewhat different view is presented, yet the two, I believe, are not irreconcilable, and if coordinated, will give us a truer conception of the whole matter than we have had before. I refer, on the one hand, to the recent vice-presidential address of Professor Wilson, ${ }^{1}$ and, on the other, to the combined work of Bateson, Punnett, Doncaster, Durham and Marryat, published in Report IV. to the Evolution Committee of the Royal Society.

In $1903^{2} \mathrm{I}$ advocated the view that sex is in-

${ }^{1}$ SCIENCE, January 8, 1909.

${ }^{2}$ Bulletin, Mus. Com. Zool., Vol. 40, p. 189. herited as a Mendelian character. The idea was not original with me. The suggestion came from the now famous Report I. of Bateson and Saunders. The fact has since come to light through Mendel's posthumously published letters ${ }^{3}$ that Mendel himself had been impressed by the parallelism between the phenomena of sex-inheritance and those of ordinary Mendelian inheritance. Indeed, the parallelism is so complete and striking that we can scarcely question the existence of a like basis for the two sets of phenomena.

Professor Wilson, to be sure, argues against what he terms "Mendelian theories" of sexheredity and advances a somewhat different theory of his own. In reality, however, his theory, while an improvement upon its predecessors, is no less Mendelian than they, but rather more so, as I shall attempt to show.

Great advance has been made since 1903 in our knowledge of Mendelian inheritance in general, as well as of sex-inheritance, and it is noteworthy that in restating our knowledge in the two fields similar changes must be made in both. For example, we formerly said regarding crosses between rodents of different colors that "gray is dominant over black" and that "black is dominant over yellow," meaning that the contrasted characteristics were antagonistic and one excluded the other in crosses. As we now look at the matter, gray is not antagonistic to black, but contains an additional element which is wanting in black. The correctness of this view is shown by the fact that black can be changed to gray by a cross which introduces that additional element. A similar relation holds between black and yollow; black is yellow plus something else, and this something else may actually be added to yellow (by a cross' with brown, for example) converting it into black.

Similarly as regards sex, in 1903 I expressed the view that male and female are antagonistic members of a Mendelian pair, one excluding the other. Such a view is inadmissible in the light of our present knowledge. What we should say is that the female is the male condition plus something else. Male-

${ }^{3}$ Abh. math.-phys. Klasse d. k. Sachs. Gesellsch. d. Wiss., Bd. 29, p. 185, Leipzig, 1905. 